\title{
Economic contraction, alcohol intoxication and suicide: analysis of the National Violent Death Reporting System
}

\author{
M S Kaplan, ${ }^{1}$ N Huguet, ${ }^{2}$ R Caetano, ${ }^{3}$ N Giesbrecht, ${ }^{4}$ W C Kerr, ${ }^{5}$ B H McFarland ${ }^{6}$
}

- Additional material is published online only. To view please visit the journal online (http://dx.doi.org/10.1136/ injuryprev-2014-041215).

${ }^{1}$ Department of Social Welfare, UCLA Luskin School of Public Affairs, Los Angeles, California, USA

${ }^{2}$ Center for Public Health Studies, Portland State University, Portland, Oregon, USA

${ }^{3}$ School of Public Health, University of Texas, Dallas, Texas, USA

${ }^{4}$ Social and Epidemiological Research Department, Centre for Addiction and Mental Health, Toronto, Ontario, Canada

${ }^{5}$ Alcohol Research Group, Public Health Institute, Emeryville, California, USA ${ }^{6}$ Department of Psychiatry, Oregon Health \& Science University, Portland, Oregon, USA

\section{Correspondence to} Dr Mark S Kaplan, Department of Social Welfare, UCLA Luskin School of Public Affairs, P.O. Box 951656, Los Angeles, CA 90095-1656, USA kaplanm@luskin.ucla.edu

Received 18 February 2014 Revised 27 May 2014 Accepted 5 June 2014

Published Online First 14 July 2014

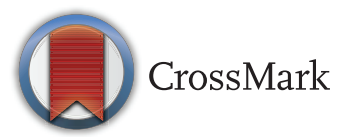

To cite: Kaplan MS, Huguet N, Caetano $R$, et al. Inj Prev 2015:21:35-41.

\section{ABSTRACT}

Objectives Although there is a large and growing body of evidence concerning the impact of contracting economies on suicide mortality risk, far less is known about the role alcohol consumption plays in the complex relationship between economic conditions and suicide. The aims were to compare the postmortem alcohol intoxication rates among male and female suicide decedents before (2005-2007), during (2008-2009) and after (2010-2011) the economic contraction in the USA.

Methods Data from the restricted National Violent Death Reporting System (2005-2011) for male and female suicide decedents aged 20 years and older were analysed by Poisson regression analysis to test whether there was significant change in the fractions of suicide decedents who were acutely intoxicated at the time of death (defined as blood alcohol content $\geq 0.08 \mathrm{~g} / \mathrm{dL}$ ) prior, during and after the downturn.

Results The fraction of all suicide decedents with alcohol intoxication increased by $7 \%$ after the onset of the recession from $22.2 \%$ in $2005-2007$ to $23.9 \%$ in 2008-2011. Compared with the years prior to the recession, male suicide decedents showed a 1.09-fold increased risk of alcohol intoxication within the first 2 years of the recession. Surprisingly, there was evidence of a lag effect among female suicide decedents, who had a 1.14-fold ( $95 \% \mathrm{Cl} 1.02$ to 1.27) increased risk of intoxication in 2010-2011 compared with 2005-2007.

Conclusions These findings suggest that acute alcohol intoxication in suicide interacts with economic conditions, becoming more prevalent during contractions.

\section{INTRODUCTION}

The global economy contracted markedly between 2007 and 2009. Although there is a large and growing body of evidence concerning the impact of contracting economies, particularly levels of unemployment, on suicide mortality risk,${ }^{1-6}$ far less is known about the role alcohol consumption plays in the complex relationship between economic conditions and suicide. Writing in The Lancet, Caan ${ }^{7}$ suggested that acute alcohol intoxication could be the missing link between unemployment and suicide.

Economic contraction and ensuing joblessness or loss of residential or health security can threaten individual identity, leading to unmet expectations, barriers to the attainment of desired roles, and/or social and economic exclusion. Compared with women, men have a higher risk for suicide following job loss. ${ }^{8-12}$ The relationship between unemployment and male suicidal behaviour has been examined in numerous international studies. ${ }^{9-13}$ According to several reviews, unemployment is associated with a twofold to threefold increased relative risk (RR) of death by suicide, compared with being employed. Aggregate-level and case-control studies generally show that unemployment is correlated with male suicide rates in several Western countries.

Based on data drawn from Danish longitudinal registers, Qin $e a^{8} l^{8}$ showed that economic stressors such as unemployment and low income increased suicide risk more in male than female subjects. The significant risk factors for men, after controlling for psychiatric conditions, were unemployment, retirement, being single and sickness-related absence from work. ${ }^{8}$ For women there were no significant risk factors other than psychiatric conditions. ${ }^{8}$

There is some evidence that the influence of unemployment varies with age. ${ }^{14} 15$ For example, Berk et $a l^{14}$ reported that the relationship between unemployment and suicide in Australia was strongest for men in the 20-34-year-old age range during the period 1968-2002. It is possible that the impact of unemployment is strongest in sensitive career-related developmental life stages.

Finally, in a study of the effects of the 2008 recession, Stuckler et $a l^{16}$ reported that short-term mortality fluctuations were mainly driven by suicides and road-traffic fatalities. In conclusion, there is extensive evidence that individuals exposed to unemployment in a contracting economy are at increased risk of suicide.

Economic conditions in the USA from 2008 through 2011 have been historically severe in terms of housing price declines, foreclosure activity, income loss and persistently high rates of unemployment. Unemployment rates rose quickly through 2008 and 2009 and were above 9\% from the spring of 2009 through the fall of 2011. Of particular importance for suicide risk are long-term unemployment rates (defined as those out of work for 27 weeks or longer). There were about six million persons in this situation each quarter from late 2009 through 2011, comprising over $40 \%$ of the unemployed in the USA during this period. Unemployment, foreclosures and other economic impacts were not evenly divided across states, counties, age groups and race/ethnicity groups with young people, African-Americans and Hispanics being disproportionately affected.

It is conceivable that economic contractions can either reduce or stimulate alcohol consumption. A reduction in disposable income may contribute to reduced spending on alcoholic beverages at the 
aggregate level; in contrast increased unemployment and accompanying strains coupled with increased leisure time may contribute to an increase in alcohol consumption. Both dimensions are discussed below.

Results from previous research on economic conditions' effects on alcohol use vary, with individual-level studies most often reporting increased alcohol use or abuse among those who experience unemployment while aggregate-level associations have been less consistent. ${ }^{17-20}$ Although some aggregatelevel studies have found a positive relationship in which alcohol consumption increases when unemployment increases, other, more methodologically rigorous studies have found a procyclical relationship. ${ }^{21-25}$ Studies conducted in the USA indicate that overall population level alcohol consumption levels are positively related to income and negatively related to unemployment. ${ }^{1925}$ The apparent paradox between these conclusions can be resolved through studies of survey data panels that include drinking pattern measures. These analyses have found that increases in state-level unemployment are associated with decreases in overall consumption, but increases in binge drinking. ${ }^{26}$ Longitudinal analyses of the National Epidemiologic Survey on Alcohol Related Conditions ${ }^{27}$ found that higher statelevel unemployment rates predicted increased binge drinking days, self-reported drunk driving and alcohol dependence. The largest effects were found for young people aged 18-24 years and African-American respondents.

Few studies have yet evaluated effects on social and health problems related to the most recent economic downturn beginning in December of 2007, the worst since the Great Depression for the USA. A study of fatal car crashes found that higher unemployment rates were associated with reduced rates of total and alcohol-related fatal crashes per mile travelled in state-level panel data, suggesting a shift in drinking to offpremise contexts. ${ }^{28}$ A new study by Kerr et $a l^{29}$ found that those under age 25 years in the 2009-2010 National Alcohol Survey drank much less than those in the 2000 and 2005 surveys, while those in their 30 s and 40s drank more through increases in heavy drinking occasions. Results suggest that poor economic prospects may reduce drinking for young people while increasing heavy drinking occasions among the middle-aged. ${ }^{29}$

The aims of this study were to (A) compare the genderspecific, age-specific and race/ethnicity-specific suicide rates before (2005-2007), during (2008-2009) and after (20102011) the economic recession; (B) estimate the fractions of acute alcohol intoxication among male and female suicide decedents before, during and after the economic downturn; (C) assess the effects of the economic contraction on the RRs of acute intoxication at the time of death by suicide after adjusting for potential confounders; and (D) evaluate the immediate and delayed effects of the economic downturn on the risk of being intoxicated at the time of death. Acute intoxication, defined as blood alcohol content (BAC) $\geq 0.08 \mathrm{~g} / \mathrm{dL}$, is based on toxicology screening of decedents as part of the coroner/medical examiner (C/ME) investigation.

\section{METHODS}

\section{Data source}

Data for suicide decedents aged 20 years and older were obtained from the National Violent Death Reporting System (NVDRS). The NVDRS is an active surveillance system that provides detailed accounts of violent deaths that occur in the participating states. In 2003, seven states participated (Alaska, Maryland, Massachusetts, New Jersey, Oregon, South Carolina,
Virginia). In 2004, 13 states participated (Alaska, Colorado, Georgia, Maryland, Massachusetts, New Jersey, North Carolina, Oklahoma, Oregon, Rhode Island, South Carolina, Virginia and Wisconsin). As of 2005, 16 states (Alaska, Colorado, Georgia, Kentucky, Maryland, Massachusetts, New Jersey, New Mexico, North Carolina, Oklahoma, Oregon, Rhode Island, South Carolina, Utah, Virginia and Wisconsin) contributed data to the NVDRS. In 2010, Ohio was added. The analyses were restricted to 2005-2011 using 16 states. The data were gathered from $\mathrm{C} / \mathrm{ME}$ records, police reports, death certificates and crime laboratories. Suicide decedents were identified as those with death certificates that listed International Classification of Diseases, 10th Revision codes X60-84 or Y87.0. ${ }^{30}$ A detailed description of the sample characteristics appears elsewhere. ${ }^{31-33}$ Pooled 2005-2011 NVDRS data yielded 65908 suicide decedents aged 20 years and older. A flow chart for the sample selection appears as online supplementary appendix 1 . The Centers for Disease Control and Prevention (CDC) Web-based Injury Statistics Query and Reporting System (2005-2010) was used to obtain suicide rates for all US states. Because of the availability of alcohol toxicology data, the study is based on the restricted-use version rather than the public-use version of the NVDRS file.

\section{Measures}

The main outcome measure of the analysis was a blood alcohol content (BAC) at or above the legal limit for intoxication while driving in the USA $(\mathrm{BAC} \geq 0.08 \mathrm{~g} / \mathrm{dL})$ versus below the limit $(\mathrm{BAC}<0.08 \mathrm{~g} / \mathrm{dL})^{34}$ at the time of suicide. BAC is part of the $\mathrm{C} /$ ME toxicological investigation. In the 16 states, $69 \%$ of male $(n=35355)$ and $73 \%$ of female $(n=10427)$ suicide decedents were tested for BAC. Blood alcohol levels were coded as a continuous measure in terms of weight by volume, and then classified as $<0.08 \mathrm{~g} / \mathrm{dL}$ or $\geq 0.08 \mathrm{~g} / \mathrm{dL}$. BAC $\geq 0.08 \mathrm{~g} / \mathrm{dL}$ was chosen to represent binge drinking as defined by the National Institute on Alcohol Abuse and Alcoholism. ${ }^{35}$ However, in an effort to determine the effect of a higher limit cut-off, a sensitivity analysis was performed using $\mathrm{BAC} \geq 0.12 \mathrm{~g} / \mathrm{dL}$ (data not shown). This supplemental analysis yielded similar results at the higher limit.

Sociodemographic variables, obtained from death certificates, included gender, age groups (20-44 years, 45-64 years, 65 years and older) and race/ethnicity (White, Black, American Indian/Alaska Native (AI/AN), Asian/Pacific Islander (Asian/PI) and Hispanic). Method of suicide was coded into firearm versus other methods (ie, poisoning, jumping, drowning, hanging and other). Economic contraction periods were defined as 20052007 (prior to the economic downturn), 2008-2009 (during the downturn) and 2010-2011 (after the downturn). The prerecession years in the NVDRS were pooled as the baseline in order to maximise statistical power.

\section{Statistical analysis}

Bivariate and multivariate analyses were performed. Suicide rates and changes in rates for all states by gender, age and race/ ethnicity were obtained from the CDC Web-based Injury Statistics Query and Reporting System. The fraction of decedents with a $\mathrm{BAC} \geq 0.08 \mathrm{~g} / \mathrm{dL}$ was estimated prior to, during and after the downturn. Poisson regression analyses were then used to test for statistically significant change in the fractions of acute intoxication between the three periods after adjusting for gender, age, race/ethnicity and suicide method. The dependent variable was the number of suicides with $\mathrm{BAC} \geq 0.08 \mathrm{~g} / \mathrm{dL}$. The primary independent variable was time period (2005-2007, 
2008-2009 and 2010-2011) entered as dummy variables. Cells in the analysis were defined by the independent variables. The 'offset term' was the number of suicides tested for alcohol in each cell. All analyses were performed using SAS (V.9.3).

\section{RESULTS}

Suicide rates overall (ie, independent of alcohol use) for all US states from before to after the recession's onset are shown in table 1 . The suicide death rate increased by $7 \%$ for the entire population with men showing a $7 \%$ increase and women a $8 \%$ rise. Especially noteworthy are the $14 \%$ increase for middleaged (45 years through 64 years) men. Among ethnic groups, suicide rates rose $9 \%$ among white and Asian/PI men but changed little for other men. Suicide rates rose for most female ethnic groups including $9 \%$ for white women, $34 \%$ for AI/AN women, 7\% for Asian/PI women. Black women and Latinas had little change in suicide rates from before to after onset of the recession.

Fractions of alcohol intoxication (BAC $\geq 0.08 \mathrm{~g} / \mathrm{dL}$ ) among suicide decedents during the study years are described in table 2. Overall, roughly one in five decedents was intoxicated at death. However, the percentage increased from the 2005 through 2007 baseline to the recession years (2008-2009) and thereafter (2010-2011). For all suicide decedents, there was a $7 \%$ increase in the intoxication fraction between 2005-2007 and 2008-2009. Furthermore, the intoxication fraction for all suicide decedents was higher by $8 \%$ when comparing 2010 2011 with $2005-2007$. There was a $1 \%$ increase in the intoxication fraction from 2008-2009 to 2010-2011.

We also examined whether the distribution of suicide by method changed over the three time periods. The results suggest that method of suicide did not change for men over

Table 1 US suicide rates* (per 100000 ) before and after the onset of the economic downturn (CDC Web-based Injury Statistics Query and Reporting System)

\begin{tabular}{|c|c|c|c|}
\hline & 2005-2007 & 2008-2010 & Per cent change \\
\hline Suicide & 14.7 (14.6 to 14.7$)$ & 15.8 (15.6 to 15.8 ) & 7 \\
\hline Male & 24.0 (23.8 to 24.1 ) & 25.7 (25.4 to 25.8 ) & 7 \\
\hline 20-44 years & 22.0 (21.8 to 22.3 ) & 22.7 (22.5 to 23.0$)$ & 3 \\
\hline $45-64$ years & 24.8 (24.5 to 25.0$)$ & 28.2 (27.9 to 28.5 ) & 14 \\
\hline 65 years+ & 28.7 (28.2 to 29.2 ) & 29.1 (28.6 to 29.6 ) & 1 \\
\hline White & 28.8 (28.6 to 29.0$)$ & 31.5 (31.3 to 31.8 ) & 9 \\
\hline Black & 12.6 (12.2 to 12.9$)$ & 12.6 (12.3 to 13.0$)$ & 0 \\
\hline Al/AN & 31.5 (29.2 to 33.8$)$ & 31.0 (28.8 to 33.2 ) & -1 \\
\hline Asian/PI & 10.3 (9.8 to 10.8 ) & $11.2(10.7$ to 11.7$)$ & 9 \\
\hline Hispanic & 12.2 (11.9 to 12.6$)$ & $12.2(11.8$ to 12.5$)$ & 0 \\
\hline Female & 6.0 (5.9 to 6.0$)$ & 6.4 (6.3 to 6.5$)$ & 8 \\
\hline 20-44 years & 5.6 (5.4 to 5.7$)$ & $5.9(5.8$ to 6.0$)$ & 6 \\
\hline $45-64$ years & 7.7 (7.5 to 7.8 ) & 8.4 (8.2 to 8.5$)$ & 9 \\
\hline 65 years+ & 4.0 (3.8 to 4.1$)$ & 4.1 (4.0 to 4.3$)$ & 4 \\
\hline White & 7.4 (7.3 to 7.5$)$ & 8.0 (7.9 to 8.2$)$ & 9 \\
\hline Black & 2.2 (2.0 to 2.3 ) & 2.3 (2.2 to 2.4 ) & 5 \\
\hline Al/AN & 7.3 (6.2 to 8.3$)$ & 9.7 (8.5 to 10.9$)$ & 34 \\
\hline Asian/PI & 4.2 (3.8 to 4.5$)$ & $4.4(4.1$ to 4.7$)$ & 7 \\
\hline Hispanic & $2.3(2.2$ to 2.5$)$ & 2.4 (2.3 to 2.6$)$ & 5 \\
\hline
\end{tabular}

time. However, for women, poisoning decreased (from $42 \%$ to $38 \%$ ) while hanging increased (from 18\% to $22 \%$ ).

For men, the intoxication fraction increased by $8 \%$ from 2005-2007 to 2008-2009, but did not change thereafter. This pattern of notable intoxication increase at the start of the recession with little change thereafter was observed for most if not all age groups among men. Among male ethnic groups, white men and AI/ANs showed increased intoxication at the recession's start and maintained those percentages during the later study years. Interestingly, black and Asian/PI men showed increased intoxication fractions at the beginning of the recession and then declined to baseline at the end of the study years. Hispanic men showed increased intoxication fractions from baseline to 2008-2009 followed by similar increase to 2010-2011. However, the increases among Hispanic men were modest.

For women overall, the intoxication fraction rose modestly (1\%) from 2005 through 2007 to 2008 and 2009 but then jumped by $13 \%$ from 2008-2009 to 2010-2011. These patterns were especially notable among women ages 20 years through 44 years whose intoxication fraction declined from the baseline to the 2008-2009 recession years followed by substantial (23\%) increase from 2008-2009 to 2010-2011. Conversely, for middle-aged ( 45 years through 64 years) women the intoxication fraction rose $12 \%$ from baseline to recession years but then only increased by 2\% from 2008-2009 to 2010-2011 . Among older women (65 years and over) the intoxication fraction jumped by $24 \%$ from baseline to recession, but then declined towards the end of the study years. White women overall showed little (1\%) change in intoxication from 20052007 to 2008-2009 but had a $10 \%$ rise thereafter. Conversely, black women had dramatic (40\%) increase of intoxication percentage from baseline to start of the recession followed by a smaller (11\%) but still noteworthy increase from 2008-2009 to 2010-2011. Native American (AI/AN) women showed decline of intoxication fraction between baseline and recession and then a return to baseline percentages during 2010-2011. Asian/PI women had an increase of $42 \%$ from 2005-2007 to 20082009 followed by a further $9 \%$ rise. Latinas had little or no change in intoxication fraction between baseline and recession but then showed a 26\% increase in the 2010 and 2011 follow-up years.

Results of the Poisson regression models, predicting alcohol intoxication, are provided in table 3 . As shown by the adjusted risk ratios, suicide decedents were 1.08 times more likely to be intoxicated at the time of death in 2008-2009 relative to 2005-2007. Conversely, there was no change in the intoxication fraction from 2008-2009 to 2010-2011. This pattern pertained especially to the youngest men whose intoxication fractions were statistically significantly elevated when comparing the baseline with either of the follow-up periods. In contrast, changes in intoxication fractions for older men were not statistically significant. Among male ethnic groups, white and black men showed a rapid increase followed by a stability pattern. However, AI/AN, Asian/PI and Hispanic men did not have risk ratios statistically significantly different from unity during the study years.

Among women, the Poisson regression models (table 3) showed no changes in adjusted intoxication risk ratio from baseline years to the 2008-2009 recession period. But, there was a delayed increase of intoxication risk ratio when comparing baseline with the 2010-2011 follow-up years. Adjusted risk ratios by age groups and for race/ethnicity subgroups were not statistically significantly different from unity over the study periods with the exception of the youngest women. Women ages 20 
Table 2 Acute intoxication (BAC $\geq 0.08 \mathrm{~g} / \mathrm{dL}$ ) among suicide decedents before (2005-2007), during (2008-2009) and after (2010-2011) the economic downturn, National Violent Death Reporting System

\begin{tabular}{|c|c|c|c|c|c|c|}
\hline & \multicolumn{3}{|c|}{ Per cent $\mathrm{BAC} \geq 0.08 \mathrm{~g} / \mathrm{dL}(95 \% \mathrm{Cl})$} & \multicolumn{3}{|c|}{ Per cent change $(95 \% \mathrm{Cl})$} \\
\hline & $\begin{array}{c}2005-2007 \\
(n=18888)\end{array}$ & $\begin{array}{c}2008-2009 \\
(n=13419)\end{array}$ & $\begin{array}{c}2010-2011 \\
(n=13475)\end{array}$ & $\begin{array}{l}2008-2009 \text { vs } \\
2005-2007\end{array}$ & $\begin{array}{l}2010-2011 \text { vs } \\
2005-2007\end{array}$ & $\begin{array}{l}2010-2011 \text { vs } \\
2008-2009\end{array}$ \\
\hline All suicides & 22.2 (21.6 to 22.8$)$ & 23.8 (23.1 to 24.5$)$ & 24.1 (23.4 to 24.8$)$ & 7 (6 to 8$)$ & $8(7$ to 9$)$ & $1(0$ to 2$)$ \\
\hline Male & 23.6 (22.9 to 24.3$)$ & 25.5 (24.7 to 26.4$)$ & 25.4 (24.6 to 26.3$)$ & 8 (7 to 9$)$ & $8(6$ to 9$)$ & $-1(-2$ to 1$)$ \\
\hline 20-44 years & $28.3(27.2$ to 29.3$)$ & 30.8 (29.5 to 32.2$)$ & $29.8(28.4$ to 31.1$)$ & 9 (7 to 11$)$ & $5(4$ to 7$)$ & $-4(-5$ to -2$)$ \\
\hline $45-64$ years & $23.8(22.6$ to 25.0$)$ & 25.4 (24.0 to 26.7$)$ & 26.5 (25.2 to 27.9$)$ & 7 (5 to 8) & 12 (10 to 13$)$ & 5 (3 to 7$)$ \\
\hline 65 years+ & 7.3 (6.3 to 8.5$)$ & $8.9(7.5$ to 10.5$)$ & 9.1 (7.8 to 10.7$)$ & 22 (20 to 24$)$ & 24 (23 to 26$)$ & $2(0$ to 4$)$ \\
\hline White & 23.7 (23.0 to 24.5$)$ & 25.5 (24.5 to 26.4$)$ & 25.4 (24.5 to 26.3$)$ & 7 (6 to 8 ) & 7 (6 to 8 ) & $0(-2$ to 1$)$ \\
\hline Black & $16.3(14.2$ to 18.6$)$ & 20.1 (17.4 to 23.2$)$ & 17.6 (14.8 to 20.8$)$ & 24 (20 to 28$)$ & $8(5$ to 12$)$ & $-13(-17$ to -8$)$ \\
\hline Al/AN & 39.8 (33.6 to 46.4$)$ & 46.7 (38.9 to 54.7$)$ & 47.6 (39.7 to 55.7$)$ & 17 (7 to 28$)$ & 20 (9 to 30$)$ & $2(-9$ to 13$)$ \\
\hline Asian/PI & $14.2(10.0$ to 19.6$)$ & 20.0 (14.7 to 26.7$)$ & $13.2(8.8$ to 19.4$)$ & 41 (34 to 49$)$ & $-7(-14$ to 0$)$ & $-34(-42$ to -26$)$ \\
\hline Hispanic & 29.7 (26.6 to 33.0$)$ & 30.9 (26.9 to 35.2$)$ & 32.1 (28.3 to 36.2 ) & $4(-1$ to 9$)$ & 8 (3 to 13$)$ & $4(-2$ to 10$)$ \\
\hline Female & $17.5(16.4$ to 18.7$)$ & 17.8 (16.4 to 19.2$)$ & 19.8 (18.4 to 21.2$)$ & $1(0$ to 3$)$ & 13 (11 to 15$)$ & 11 (9 to 13 ) \\
\hline 20-44 years & $21.0(19.3$ to 23.0$)$ & 19.4 (17.4 to 21.7$)$ & 23.9 (21.7 to 26.3$)$ & $-8(-11$ to -5$)$ & 14 (11 to 17$)$ & 23 (20 to 26 ) \\
\hline $45-64$ years & $16.4(14.7$ to 18.1$)$ & $18.3(16.3$ to 20.5$)$ & 18.7 (16.8 to 20.9$)$ & 12 (9 to 15$)$ & 14 (12 to 17$)$ & $2(-1$ to 5$)$ \\
\hline 65 years+ & 6.7 (4.7 to 9.5$)$ & $8.3(5.7$ to 12.0$)$ & $7.2(4.8$ to 10.6$)$ & 24 (20 to 28$)$ & 7 (4 to 11$)$ & $-13(-18$ to -9$)$ \\
\hline White & 17.6 (16.4 to 18.9$)$ & $17.8(16.3$ to 19.3$)$ & 19.4 (17.9 to 20.9$)$ & $1(-1$ to 3$)$ & 10 (8 to 12$)$ & 9 (7 to 11$)$ \\
\hline Black & $10.8(7.3$ to 15.7$)$ & 15.1 (10.1 to 21.8$)$ & 16.8 (11.3 to 24.2$)$ & 40 (32 to 47 ) & 55 (48 to 63$)$ & 11 (3 to 20$)$ \\
\hline Al/AN & 40.4 (28.5 to 53.5$)$ & 27.5 (17.0 to 41.2$)$ & $40.0(27.5$ to 54.0$)$ & $-32(-50$ to -14$)$ & $-1(-19$ to 18$)$ & 46 (27 to 64$)$ \\
\hline Asian/PI & 8.2 (4.1 to 15.5 ) & 11.6 (6.5 to 19.7$)$ & 12.7 (7.0 to 22.0$)$ & 42 (33 to 50$)$ & 55 (46 to 64$)$ & $9(0$ to 19$)$ \\
\hline Hispanic & 21.9 (16.1 to 28.9$)$ & 23.5 (16.1 to 32.9$)$ & 27.6 (20.7 to 35.8 ) & $7(-3$ to 18$)$ & 26 (16 to 36$)$ & 18 (6 to 29 ) \\
\hline
\end{tabular}

Per cent change $=\left(\left(\right.\right.$ rate period $^{\mathrm{n}+1}-$ rate period $\left.^{\mathrm{n}}\right) /$ rate period $\left.^{\mathrm{n}}\right) \times 100$.

Al/AN, American Indian/Alaska Native; Asian/PI, Asian/Pacific Islander; BAC, blood alcohol content.

years through 44 years showed decline in RR of intoxication when comparing 2010-2011 with 2008-2009.

\section{DISCUSSION}

The results of the present study clearly demonstrate that the percentages of suicide decedents who were intoxicated increased during the recent economic contraction. The findings also show that most demographic groups were impacted. Equally important, the data show the broad salience of alcohol involvement in suicide during times of economic hardship. At the population level, economic recessions have been associated with declines in overall alcohol consumption, ${ }^{25}$ an effect also seen during 2009 and $2010,{ }^{36}$ but also with increases in detrimental drinking patterns and alcohol-related problems, particularly among those directly affected by the recession. ${ }^{27}$ Economic downturns have also been linked to reduced mortality rates, particularly for heart problems and traffic crashes, with suicides being the clearest exception. $^{23}$

Our results show that suicide mortality rose during the 20082009 recession, consistent with the expected positive relationship between unemployment rates and suicide. Conversely, given the decline in alcohol sales during the recession, ${ }^{36}$ this finding is contrary to the established positive relationship between alcohol sales and suicide mortality. ${ }^{37} 38$ This contradiction can be explained through the apparent effect of economic contraction on the proportion of suicides where the decedent's BAC was greater than 0.08 , indicating acute alcohol intoxication. Analyses of NVDRS data show a statistically significant absolute increase of about two percentage points in the proportion of suicides involving acute intoxication when comparing the 2008-2009 period with the pre-recession period from 2005 to 2007 . Moreover, this increased percentage was maintained in 2010-2011. These findings suggest that alcohol-linked suicides become more prevalent during economic contractions. Our findings also suggest that about half of the increase in suicides occurring during the economic downturn may have been among intoxicated decedents.

Consistent with previous research, the present analysis showed noticeable gender differences in how the 2008-2009 recession and accompanying socioeconomic sequelae were associated with increased stress-related outcomes such as problem drinking ${ }^{39}$ and suicide. ${ }^{40}$ The results show that men were more vulnerable to the initial phase of the economic contraction. Chang $e t a l^{40}$ suggest that this finding may be because men are more likely to be the main earner in the family, may experience shame because of being unemployed and are less likely to seek help. Unemployed men are more likely to experience social isolation $^{41}$ along with an accompanying risk for alcohol misuse. ${ }^{42}$ On the other hand, previous analyses indicate that women seem less likely to inflict self harm in response to unemployment, suggesting an increased degree of resilience among women. ${ }^{4}$ However, the present study demonstrates, that while (at least initially) women may be protected by the type of occupation they hold, ${ }^{43}$ their help-seeking behaviour ${ }^{40}$ and levels of resilience ${ }^{4}$ erosion of these protective mechanisms as well as the accumulation overtime of uncertainty and financial strain ${ }^{44} 45$ might lead to the observed delayed effect.

The different unemployment rate trajectories may have played a role in the delayed rise in women's alcohol-related suicides as compared with men's. In 2008 the unemployment rate for women aged 20 years and older rose more slowly than that for men reaching a peak rate of $8.3 \%$ in November of 2010 compared with $10.7 \%$ for men in November of 2009 (according to Bureau of Labour Statistics official rates from the Current Population Survey). ${ }^{46}$ Women's unemployment rates were also essentially flat through 2010 and 2011, while men's rates showed some improvement after their peak. Further, overall long-term unemployment (27 weeks or longer) rose steeply 
Table 3 Acute intoxication (BAC $\geq 0.08 \mathrm{~g} / \mathrm{dL}$ ) among suicide decedents during and after the economic downturn, National Violent Death Reporting System

\begin{tabular}{llll}
\hline & Risk ratio $(\mathbf{9 5} \% \mathrm{Cl})$ & & \\
\cline { 2 - 3 } & 2008-2009 vs $2005-\mathbf{2 0 0 7}$ (ref) & 2010-2011 vs 2005-2007 (ref) & $0.99(0.94$ to 1.04$)$ \\
\hline All suicides & $1.08(1.03 \text { to } 1.13)^{* *}$ & $1.10(1.05 \text { to } 1.15)^{* * *}$ & $1.01(0.95$ to 1.06$)$ \\
Male & $1.09(1.04 \text { to } 1.15)^{* * *}$ & $1.09(1.04 \text { to } 1.15)^{* * *}$ & $1.05(0.97$ to 1.13$)$ \\
20-44 years & $1.10(1.02 \text { to } 1.17)^{* *}$ & $1.05(0.98$ to 1.12$)$ & $0.96(0.88$ to 1.04$)$ \\
45-64 years & $1.08(0.99$ to 1.17$)$ & $1.12(1.03 \text { to } 1.22)^{* *}$ & $0.97(0.76$ to 1.24$)$ \\
65 years+ & $1.21(0.96$ to 1.54$)$ & $1.25(0.99$ to 1.57$)$ & $1.00(0.94$ to 1.06$)$ \\
White & $1.08(1.02 \text { to } 1.14)^{* *}$ & $1.09(1.03 \text { to } 1.15)^{* *}$ & $1.15(0.90$ to 1.47$)$ \\
Black & $1.26(1.01 \text { to } 1.57)^{*}$ & $1.09(0.86$ to 1.39$)$ & $0.97(0.70$ to 1.35$)$ \\
Al/AN & $1.13(0.83$ to 1.55$)$ & $1.17(0.85$ to 1.60$)$ & $1.48(0.86$ to 2.55$)$ \\
Asian/PI & $1.41(0.86$ to 2.32$)$ & $0.95(0.54$ to 1.67$)$ & $0.99(0.79$ to 1.23$)$ \\
Hispanic & $1.08(0.88$ to 1.32$)$ & $1.09(0.89$ to 1.33$)$ & $0.90(0.80$ to 1.01$)$ \\
Female & $1.03(0.92$ to 1.15$)$ & $1.14(1.02 \text { to } 1.27)^{*}$ & $0.82(0.69 \text { to } 0.97)^{*}$ \\
20-44 years & $0.93(0.79$ to 1.09$)$ & $1.14(0.98$ to 1.32$)$ & $0.97(0.82$ to 1.16$)$ \\
45-64 years & $1.12(0.95$ to 1.33$)$ & $1.15(0.98$ to 1.36$)$ & $1.14(0.65$ to 2.02$)$ \\
65 years+ & $1.24(0.73$ to 2.13$)$ & $1.09(0.63$ to 1.89$)$ & $0.91(0.80$ to 1.04$)$ \\
White & $1.02(0.90$ to 1.15$)$ & $1.11(0.99$ to 1.25$)$ & $0.87(0.48$ to 1.57$)$ \\
Black & $1.38(0.77$ to 2.48$)$ & $1.59(0.89$ to 2.86$)$ & $0.67(0.34$ to 1.34$)$ \\
Al/AN & $0.65(0.34$ to 1.27$)$ & $0.97(0.53$ to 1.77$)$ & $0.90(0.38$ to 2.13$)$ \\
Asian/PI & $1.47(0.59$ to 3.67$)$ & $1.63(0.64$ to 4.17$)$ & $0.84(0.50$ to 1.42$)$ \\
Hispanic & $1.13(0.66$ to 1.91$)$ & $1.33(0.84$ to 2.12$)$ & \\
\hline
\end{tabular}

Risk ratios and $95 \%$ Cls from Poisson regression models adjusted for gender, age, race/ethnicity and method of suicide (firearm vs other methods). ${ }^{*} \mathrm{p}<0.05 ;{ }^{* *} \mathrm{p}<0.01 ;{ }^{* * *} \mathrm{p}<0.001$. Al/AN, American Indian/Alaska Native; Asian/PI, Asian/Pacific Islander; BAC, blood alcohol content; ref, reference.

though 2009 and remained at a high level in 2010 and 2011. This type of unemployment is expected to cause hardships in families over time through increasing economic difficulties, longer-term privations and deteriorating mental health, putting strains on family relationships in circles widening out from those affected and further increasing the mental burden on those directly affected as their problems impact others. Through these mechanisms, more women may have been driven into detrimental drinking patterns and mental health problems leading to alcohol-related suicides.

It should be noted that this study has several potential limitations. First, postmortem toxicology testing rates varied across the NVDRS states. Fortunately, only 3 of the 16 states (Alaska, Georgia and Oregon) had alcohol testing rates below the 50\% level. Toxicology testing is often determined by availability of state funding. Unfortunately, current federal resources provided to the NVDRS states do not cover toxicological testing. Additionally, there is some selection bias towards testing. For example, women who were more likely to die from poisoning were also more likely to have been tested for alcohol. However, all demographic subgroups had toxicological testing rates at or above $65 \%$ except those aged 60 years and older whose testing rate was slightly lower (62\%). In addition, a supplementary sensitivity analysis showed that the exclusion of states with lower testing rates did not alter the original findings. Second, the NVDRS only contains data on suicide decedents and not information on attempters. Third, NVDRS does not have information on the drinking patterns of the decedents while they were alive. It is conceivable that for some decedents this episode was their first time drinking in response to the economic crisis. Interestingly, there is some evidence ${ }^{47}$ that individuals who were intoxicated at the time of their death did not have a history of alcohol misuse prior to their suicide. Finally, the present analysis did not focus on yearly or more frequent (eg, quarterly) trends and did not incorporate data on unemployment rates or other measures of economic conditions.

These limitations notwithstanding, the NVDRS has multiple strengths. First, the NVDRS data set provides BAC information for most suicide decedents. Second, the NVDRS provides recent data, which allow this study to take advantage of a natural experiment, the contracting of the economy, to examine the influence of economic hardships on suicide involving acute alcohol intoxication. Third, although the NVDRS states are not necessarily representative of the USA, the decedents in these 16 states are similar to the demographic profile for the country as a whole in terms of gender, age, ethnic/racial composition, urban/ rural characteristics and national suicide mortality rates. ${ }^{31}$ Finally, collection of postmortem data is particularly challenging when states have decentralised medicolegal death investigation systems rather than a centralised medical examiner system. It is worth noting that $69 \%$ of the states participating in the NVDRS have a centralised medical examiner system compared with only $15 \%$ of non-NVDRS states. ${ }^{48}$

The relationships among economic contraction, alcohol use and suicide are complex with acute and long-term influences of drinking and unemployment on suicide risk. ${ }^{38}$ Unemployment is one of the most salient features of the economic contraction in 2008-2009, but further research is needed to distinguish the impact of unemployment from other changes such as the decline in the gross domestic product, falling housing prices, increased home foreclosures and heightened investment losses. Because the timing and locations of these factors differ across states, future studies by this research team will attempt to disentangle these influences.

Finally, individuals experiencing the effects of economic contraction such as long-term unemployment or home foreclosure are important targets for public health interventions. For example, integrated mental health and substance abuse services 
as well as more generous unemployment income assistance may be necessary for those who have suffered the prolonged effects of the economic crisis.

\section{What is already known on the subject}

- Suicides tend to increase during periods of economic downturn.

- Younger men appear to be particularly vulnerable to the effects of economic contraction.

- About a third of all suicide decedents are intoxicated at the time of death.

\section{What this study adds}

- Alcohol intoxication among suicide decedents increased after the start of the 2008-2009 economic downturn.

- Male suicide decedents' risk of intoxication rose immediately after the start of the economic downturn.

- Female suicide decedents experienced a delayed effect in their risk of alcohol intoxication.

Contributors MSK originated the study, led the writing, and synthesised the analyses. MSK and WCK provided important intellectual content and helped draft the manuscript. MSK and NH acquired the data. BHMcF provided statistical expertise. WCK, RC and NG helped conceptualise ideas, interpret findings and review drafts of the manuscript. All the authors reviewed and approved the final draft.

Funding This study was supported by grant R01 AA021791 from the National Institute on Alcohol Abuse and Alcoholism. All analyses, interpretations and conclusions based on the analysis of these data are solely the responsibility of the authors and do not represent the views of either the US Centers for Disease Control and Prevention or the states participating in the National Violent Death Reporting System.

\section{Competing interests None.}

Ethics approval Ethics approval was provided by the University of California, Los Angeles Institutional Review Board.

Provenance and peer review Not commissioned; externally peer reviewed.

\section{REFERENCES}

1 Brenner MH. Mental illness and the economy. Cambridge, MA: Harvard University Press, 1973.

2 Zivin K, Paczkowski M, Galea S. Economic downturns and population mental health: research findings, gaps, challenges and priorities. Psychol Med 2011;41:1343-8

3 Luo F, Florence CS, Quispe-Agnoli M, et al. Impact of business cycles on US suicide rates, 1928-2007. Am J Public Health 2011;101:1139-46.

4 Barr B, Taylor-Robinson D, Scott-Samuel A, et al. Suicides associated with the 200810 economic recession in England: time trend analysis. BMJ 2012;345:e5142.

5 Maki N, Martikainen P. A register-based study on excess suicide mortality among unemployed men and women during different levels of unemployment in Finland. J Epidemiol Community Health 2012;66:302-7.

6 Nandi A, Prescott MR, Cerda M, et al. Economic conditions and suicide rates in New York City. Am J Epidemiol 2012;175:527-35.

7 Caan W. Unemployment and suicide: is alcohol the missing link? Lancet 2009;374:1241-2.

8 Qin P, Agerbo E, Mortensen PB. Suicide risk in relation to socioeconomic, demographic, psychiatric, and familial factors: a national register-based study of all suicides in Denmark, 1981-1997. Am J Psychiatry 2003;160:765-72.

9 Jin RL, Shah CP, Svoboda TJ. The impact of unemployment on health: a review of the evidence. CMAJ 1995;153:529-40.

10 Ying YH, Chang K. A study of suicide and socioeconomic factors. Suicide Life Threat Behav 2009;39:214-26
11 Morrell S, Taylor R, Quine S, et al. Suicide and unemployment in Australia 1907-1990. Soc Sci Med 1993:36:749-56.

12 Eliason M, Storrie D. Job loss is bad for your health-Swedish evidence on cause-specific hospitalization following involuntary job loss. Soc Sci Med 2009;68:1396-406.

13 Walsh S, Charnigo R. An ecological approach to preventing suicide using the national violent death reporting system and county level health status data. Suicidology Online 2012;3:92-101.

14 Berk M, Dodd S, Henry M. The effect of macroeconomic variables on suicide. Psychol Med 2006;36:181-9.

15 Chen EY, Chan WS, Wong PW, et al. Suicide in Hong Kong: a case-control psychological autopsy study. Psychol Med 2006;36:815-25.

16 Stuckler D, Basu S, Suhrcke M, et al. Effects of the 2008 recession on health: a first look at European data. Lancet 2011;378:124-5.

17 Catalano R, Dooley D, Wilson G, et al. Job loss and alcohol abuse: a test using data from the Epidemiologic Catchment Area project. J Health Soc Behav 1993;34:215-25.

18 Ettner SL. Measuring the human cost of a weak economy: does unemployment lead to alcohol abuse? Soc Sci Med 1997:44:251-60.

19 Janlert U, Hammarstrom A. Alcohol consumption among unemployed youths: results from a prospective study. Br J Addict 1992;87:703-14

20 Mossakowski KN. Is the duration of poverty and unemployment a risk factor for heavy drinking? Soc Sci Med 2008;67:947-55.

21 Catalano R, Goldman-Mellor S, Saxton K, et al. The health effects of economic decline. Annu Rev Public Health 2011;32:431-50.

22 Freeman DG. Alternative panel estimates of alcohol demand, taxation, and the business cycle. South Econ J 2000;67:325-44.

23 Gerdtham UG, Ruhm CJ. Deaths rise in good economic times: evidence from the OECD. Econ Hum Biol 2006;4:298-316

24 Krüger NA, Svensson M. Good times are drinking times: empirical evidence on business cycles and alcohol sales in Sweden 1861-2000. Appl Econ Lett 2003; 17:543-6.

25 Ruhm CJ, Black WE. Does drinking really decrease in bad times? J Health Econ 2002;21:659-78

26 Dee TS. Alcohol abuse and economic conditions: evidence from repeated cross-sections of individual-level data. Health Econ 2001;10:257-70.

27 Davalos ME, Fang $\mathrm{H}$, French MT. Easing the pain of an economic downturn: macroeconomic conditions and excessive alcohol consumption. Health Econ 2012:21:1318-35.

28 Cotti C, Tefft N. Decomposing the relationship between macroeconomic condition and fatal car crashes during the great recession: alcohol- and non-alcohol-related accidents. B E J Econom Anal Policy 2011:11:48.

29 Kerr WC, Greenfield TK, Ye Y, et al. Are the 1976-1985 birth cohorts heavier drinkers? Age-period-cohort analyses of the National Alcohol Surveys 1979-2010. Addiction 2013;108:1038-48.

30 World Health Organization. International Classification of Diseases. 10th Revision. Geneva, Switzerland: World Health Organization, 1996.

31 Kaplan MS, McFarland BH, Huguet N, et al. Acute alcohol intoxication and suicide: a gender-stratified analysis of the National Violent Death Reporting System. Inj Prev 2013:19:38-43.

32 Caetano R, Kaplan MS, Huguet N, et al. Acute alcohol intoxication and suicide among United States ethnic/racial groups: findings from the national violent death reporting system. Alcohol Clin Exp Res 2013:37:839-46.

33 Karch DL, Logan J, McDaniel D, et al. Surveillance for violent deaths - National Violent Death Reporting System, 16 states, 2009. MMWR Surveill Summ 2012;61:1-43.

34 U.S. Department of Transportation. National Transportation Statistics. 2010. http:/ www.bts.gov/publications/national_transportation_statistics (accessed 4 Jan 2013)

35 National Institute on Alcohol Abuse and Alcoholism. Moderate \& binge drinking. n. d.; http://www.niaaa.nih.gov/alcohol-health/overview-alcoholconsumption/moderate-binge-drinking (accessed 11 Jun2013).

36 LaVallee RA, Yi H-y. Apparent per capita alcohol consumption: national, state, and regional trends, 1977-2010. (Surveillance Report \#95). Bethesda, MD: U.S Department of Health and Human Services, Public Health Service, National Institutes of Health, 2012

37 Ramstedt M. Alcohol and suicide in 14 European countries. Addiction 2001;96:59-75

38 Kerr WC, Subbaraman M, Ye Y. Per capita alcohol consumption and suicide mortality in a panel of US states from 1950 to 2002. Drug Alcohol Rev 2011:30:473-80

39 Bor J, Basu S, Coutts A, et al. Alcohol use during the great recession of 20082009. Alcohol Alcohol 2013:48:343-8.

40 Chang SS, Stuckler D, Yip P, et al. Impact of 2008 global economic crisis on suicide: time trend study in 54 countries. BMJ 2013;347:f5239.

41 Goldman-Mellor SJ, Saxton KB, Catalano RC. Economic Contraction and Mental Health. Int J Ment Health 2010;39:6-31.

42 Bartley M. Unemployment and ill health: understanding the relationship. J Epidemio Community Health 1994;48:333-7. 
43 Queneau H, Sen A. Evidence on the dynamics of unemployment by gender. App/ Econ 2008;40:2099-108.

44 McLaughlin KA, Nandi A, Keyes KM, et al. Home foreclosure and risk of psychiatric morbidity during the recent financial crisis. Psychol Med 2012;42:1441-8

45 Bennett GG, Scharoun-Lee M, Tucker-Seeley R. Will the public's health fall victim to the home foreclosure epidemic? PLOS Med 2009;6:e1000087.
46 United States Department of Labor. U.S. Bureau of Labor Statistics. U.S. Government Printing Office: Washington, DC, 2013.

47 Kaplan MS, Huguet N, McFarland BH, et al. Use of alcohol before suicide in the United States. Ann Epidemiol 2014. Published online 26 May 2014. doi:10.1016/j. annepidem.2014.05.008

48 National Research Council. Strengthening forensic science in the USA: a path forward. Washington, DC: The National Academies Press, 2009.

\section{Improved safety reduces insurance premium rates}

Saskatchewan employee insurance rates have fallen for the eighth successive year and are now the lowest since 1986. This is largely due to fewer injuries resulting from the adoption last year of Mission: Zero by most employers.

\section{Hospitalised injuries in Australian children}

Age and injury are more closely linked at some periods of life than others. As expected, boys were injured twice as often as girls, and rates were higher for older age groups, in rural and remote areas, and for Aboriginal and Torres Strait Islander children and young people. Source: Hospitalised injury in children and young people 2011-2012. Injury research and statistics series no. 91. Cat. no. INJCAT 167. Canberra: AlHW.

\section{No charges for speeding police}

A Quebec court decided not to lay charges against a police officer who crashed into another car while going $120 \mathrm{kmph}$ in a $50 \mathrm{kmph}$ zone, killing a 5 -year old. The officer was tailing an offender suspected of a white collar crime. The investigation concluded the child's father was partly to blame because he should have waited for a flashing green light before turning!

Editor's Comment: Following public outcries, an enquiry is to be held.

\section{Reforms needed to improve road safety}

At a meeting in Qatar, experts, including participants from Geneva, Turkey, Belgium, UK, UAE and Lebanon, urged transport authorities to implement reforms to improve road safety. The reforms involve steps to enhance the competence of drivers, especially those carrying hazardous goods, school buses, trailers and taxis. 